\title{
Pulmonary Manifestations of Sjögren's Syndrome
}

\author{
George Stojan ${ }^{1}$ [Fellow in Rheumatology], Alan N. Baer ${ }^{2}$ [Associate Professor of \\ Medicine], and Sonye K. Danoff ${ }^{3}$ [Associate Professor of Medicine] \\ ${ }^{1}$ Division of Rheumatology, Department of Medicine, Johns Hopkins University School of \\ Medicine, Baltimore, MD \\ 2Division of Rheumatology, Department of Medicine, Johns Hopkins University School of \\ Medicine, Baltimore, MD \\ ${ }^{3}$ Division of Pulmonary Medicine and Critical Care, Department of Medicine, Johns Hopkins \\ University School of Medicine, Baltimore, MD
}

\section{Keywords}

cystic lung disease; non-specific interstitial pneumonia; lymphocytic interstitial pneumonia; pulmonary amyloidosis; xerotrachea; cough; bronchus-associated lymphoid tissue; chronic obstructive pulmonary disease; epistaxis; nasal septal perforation; hoarseness; bamboo node; follicular bronchitis; follicular bronchiolitis; pulmonary hypertension

\section{Introduction}

Sjögren's syndrome (SS) is a chronic systemic autoimmune disease characterized by lymphocytic infiltration of exocrine glands and other organs with resultant keratoconjunctivitis sicca, salivary hypofunction, and various extraglandular manifestations (1). It occurs either as a primary disorder or in association with other connective tissue diseases (secondary SS). An estimated 0.4 million to 3.1 million adults in the US had primary SS in 2005 (2).

The prevalence of pulmonary involvement in patients with SS is difficult to estimate. The classification criteria for SS have changed over time and both study design and patient populations have varied. In large series, the estimated prevalence of clinically significant lung involvement is between 9-24\% (3-5). On the other hand, evaluation of asymptomatic patients with pulmonary function tests (PFTs), bronchoalveolar lavage, and computed tomography detected abnormalities in up to $75 \%$ of patients (6). Pulmonary manifestations in SS typically develop late in the course of disease and are rarely the presenting feature (7). Lesions affecting the small airways, such as follicular bronchiolitis, are among the most common histologic findings in SS patients with pulmonary involvement. Patients with SSrelated lung disease report impaired quality of life and impaired physical functioning compared with other SS patients (3). Importantly, pulmonary involvement is associated with a 4-fold increased mortality risk after 10 years of disease (3).

Corresponding Author: Sonye K. Danoff, MD, PhD, Associate Professor of Medicine, Division of Pulmonary Medicine and Critical Care, Johns Hopkins University School of Medicine, 1830 Monument Street, $5^{\text {th }}$ floor, Baltimore, MD 21287. 


\section{Upper airway disease}

Nasal crusting and epistaxis are common symptoms in SS and were reported, respectively, by $18.5 \%$ and $31.8 \%$ of patients in one series (8). Nearly one half of patients with SS in this series had nasal crusting and dryness on physical examination. Chronic sinusitis was also reported secondary to inspissated secretions.

Hoarseness is reported by approximately one third of SS patients. It is associated with the presence of dryness or thick mucus coating the vocal cords. Rarely, hoarseness may indicate the presence of vocal fold lesions. A bamboo node is a white or yellow transverse submucosal lesion of the vocal folds that has been described in SS (9). Granulomatous and non-granulomatous laryngeal nodules have also been described (10).

Fifty percent of primary SS patients report having a constant dry cough that impairs their quality of life (11)(12). When present as an isolated symptom with an unremarkable radiological and functional evaluation, the term xerotrachea is used. In a study by Mathieu et al, the tracheobronchial mucociliary clearance in SS patients was significantly lower compared to controls, $3.3 \pm 1.2 \mathrm{~mm} / \mathrm{min}$ vs $5.9 \pm 1.1 \mathrm{~mm} / \mathrm{min}$. Interestingly, patients with xerotrachea had undetectable mucociliary clearance (13). Xerotrachea is classically described in pathology literature as being associated with lymphocytic inflammation and atrophy of the submucosal glands (14); however bronchial gland atrophy was not evident in a morphometric analysis of goblet cells and bronchial glands in SS patients compared to controls (15). This raises the possibility of a functional, rather than structural, glandular defect. Patients with xerotrachea usually have difficulty clearing thickened secretions and are thus predisposed to atelectasis, bronchiectasis, recurrent bouts of bronchitis and bronchopneumonia, as well as peribronchial and peribronchiolar scarring with airway narrowing (14).

\section{Distal airway disease}

Follicular bronchiolitis (FB) is one of the most common pulmonary manifestations of SS. FB is a rare type of cellular bronchiolitis characterized by the presence of hyperplastic lymphoid follicles with reactive germinal centers, distributed along the bronchovascular bundles (13). The lymphoid infiltrate is confined to bronchioles and the immediate peribronchiolar interstitium without significant extension into parenchyma. This latter features distinguishes FB from lymphocytic interstitial pneumonia (LIP), in which such parenchymal extension is observed (16). In a study of endobronchial biopsies from nonsmoking SS patients and control subjects, the SS patients had an increased number of CD4positive $T$ cells in the lamina propria outside of the bronchial submucosal glands(17). Peribronchiolar mononuclear cell infiltration may cause airway narrowing due to a ballvalve mechanism, and ultimately lead to bullae formation (18) but this proposed mechanism cannot explain the formation of cysts and bullae in other organs, for example the thymus (19). The profile of the inflammatory infiltrate in the airways of patients with SS is similar to that of atopic asthma, and includes a large number of mast cells and neutrophils in addition to lymphocytes(17). This inflammatory infiltrate causes bronchial hyperreactivity (18) manifested by dry cough, recurrent "bronchitis" and dyspnea (3). The overexpression of 
IL-12 in the lungs of mice resulted in bronchial and alveolar abnormalities strikingly similar to those found in the lungs of SS patients with lymphocytic infiltrates around the bronchi, increased cell proliferation in the alveolar region, and increased interstitial and alveolar macrophages leading to decreased mucociliary clearance and increased oxidative stress (20). The role played by IL-12 and other cytokines in the evolution of SS lung disease remains to be elucidated. The most common radiographic findings are nodules ranging in size from 1 to $3 \mathrm{~mm}$ with a predominant centrilobular distribution, while cystic forms secondary to bronchiolar obstruction are rare (19). PFTs classically show restrictive disease and the diffusing capacity $\left(\mathrm{DL}_{\mathrm{CO}}\right)$ appears to be the most sensitive test (19). The clinical course and prognosis for most patients with isolated follicular bronchiolitis is relatively good, and progressive lung disease is uncommon (20).

\section{Chronic Obstructive Pulmonary Disease (COPD)}

In a cohort from Sweden, 37\% of primary SS patients fulfilled COPD criteria over 11 years of followup (21). COPD was 5 times more prevalent among ever smokers, but even the prevalence among non-smokers was unexpectedly high. Primary SS patients had significantly decreased VC, TLC, $\mathrm{FEV}_{1}, \mathrm{FEV}_{1} / \mathrm{VC}$ and $\mathrm{DL}_{\mathrm{CO}}$ while the $\mathrm{RV}$ was increased in comparison with expected values. Respiratory symptoms, radiological abnormalities, and inflammatory and serological features of disease had no association with PFT variables, although in previous studies, an association was shown between PFT variables and anti-SSA antibodies (22), focal sialadenitis (22), hypergammaglobulinaemia, and $\beta_{2}$-microglobulin (23).

\section{Interstitial Lung Disease}

Interstitial lung disease (ILD) refers to a group of lung diseases affecting the interstitium of the lung: alveolar epithelium, pulmonary capillary endothelium, basement membrane, and perivascular and perilymphatic tissues (24). Historically, the predominant form of ILD in primary SS was deemed to be lymphocytic interstitial pneumonitis (LIP). In a case series by Parambil et al (25) only $17 \%$ of primary SS patients with ILD had a histologic diagnosis of LIP. This rather dramatic change in prevalence of LIP could be the result of revisions of histopathologic criteria for LIP so that more cases are categorized as nonspecific interstitial pneumonia (NSIP) based on the degree of lymphocytic infiltration. Currently, NSIP is the most common subtype of ILD in SS patients, with a prevalence ranging between 28\% (25) and $61 \%$ (26). The role of the autoantibody profile in the etiopathogenesis of ILD is unknown, but anti-SSA antibody positivity even in the absence of other SS criteria has been shown to be associated with an NSIP pattern on imaging and more severe lung function impairment (27).

\section{Nonspecific Interstitial Pneumonia (NSIP)}

NSIP is characterized histologically by varying proportions of interstitial inflammation and fibrosis that are temporally uniform. The most common presenting complaint is dyspnea for several months, and chest radiographs usually show bilateral interstitial infiltrates. The characteristic findings on high resolution computed tomography (HRCT) include groundglass opacities with subpleural and basilar predominance, seen in $75 \%$ of cases (28). 
Reticular abnormalities, with or without traction bronchiectasis, are common and appear to correlate with the amount of fibrosis observed histopathologically. Two findings that correlate with the histological diagnosis of NSIP are subpleural sparing and tracking of opacities along lower-zone bronchovascular bundles (28). Honeycombing is rare in NSIP and is often considered an exclusion factor. The prognosis is good and is dependent on the presence or absence of fibrosis. In a case series by Katzenstein et al (29), no deaths occurred in the patients whose biopsies showed pure inflammation without fibrosis, while the mortality rate was $11 \%$ for those ILD patients with fibrosis.

\section{Lymphocytic interstitial pneumonia (LIP)}

Carrington and Liebow described the first case of LIP (30). It is characterized histopathologically by diffuse interstitial infiltration of lymphocytes and plasma cells that diffusely expands the alveolar septa and small airways. LIP differs from the pattern of involvement seen in lymphoma, which is nearly always distributed along bronchovascular bundles, pleura, and interlobular septa. Patients nearly always present with respiratory symptoms, including cough and slowly progressive dyspnea, sometimes associated with pleuritic chest pain $(31,32)$. PFTs typically reveal a restrictive pattern with reduced $\mathrm{DL}_{\mathrm{CO}}$ (33). Chest radiography usually demonstrates bilateral reticular or reticulonodular opacities that are more prominent in the lower lung zones. The most common CT findings are diffuse ground-glass opacity and consolidation, with occasional thin-walled cysts, presumably due to follicular bronchiolitis (28). Patients with LIP generally respond well to initial corticosteroid therapy, but up to one third may die within several years of diagnosis from progression of disease or infectious complications related to immunosuppressive therapy (16).

\section{Usual Interstitial Pneumonia (UIP)}

The histopathology of UIP is one of destructive fibrosis alternating with normal lung. The prevalence of UIP among SS patients with ILD is 17\% (25). Patients may be asymptomatic in the initial stages of disease, but most often present with progressive dyspnea and dry cough. Pulmonary function tests reveal evidence of restriction and impaired gas exchange (34). The classic findings on HRCT include bibasilar reticular abnormalities with honeycombing (35). Among all the ILD subtypes associated with CTD, UIP has the worst prognosis and this is true for SS as well. All three patients with UIP in the series by Parambil et al had progressive lung disease with no response to corticosteroid therapy (25).

\section{Organizing Pneumonia (OP)}

$\mathrm{OP}$ is a relatively rare clinicopathologic entity characterized by intraluminal inflammatory debris composed of masses of fibroblasts and myofibroblasts in the alveolar ducts and airspaces with coexistent chronic inflammation of the surrounding alveoli (36). Clinical findings of progressive dyspnea, low grade fever, constitutional symptoms, and pulmonary infiltrates that are unresponsive to antibiotic therapy should raise the possibility of organizing pneumonia. PFTs most commonly show a mild to moderate restrictive ventilatory defect with a reduced $\mathrm{DL}_{\mathrm{CO}}(37,38)$. The typical CT pattern consists of peripheral parenchymal consolidations with air bronchograms and variable associated ground-glass opacities. Corticosteroids are the mainstay of therapy and response is seen 
within several days to a few weeks. The optimum dose and length of treatment is not known and relapses are common (39).

\section{Cystic Lung Disease}

Cystic lung disease is found in up to $10 \%$ of primary SS patients $(6,26)$. Besides being a primary finding, cysts can accompany other pulmonary complications of primary SS, including amyloidosis (40-42), malignant lymphoma (26) and lymphocytic interstitial pneumonia (43). The lower lobes are predominantly affected (Figure 1). Pulmonary function tests show a variable mixed restrictive and obstructive pattern. On PFTs, the number of small cysts on HRCT appears to correlate with the severity of obstructive findings and the severity of interstitial inflammation appears to correlate with the restrictive findings (19). Cysts, like fibrosis, are an irreversible manifestation of pulmonary SS and early diagnosis and treatment, especially in cases associated with LIP, may successfully halt the process (44).

\section{Pulmonary Lymphoma}

Mucosa-associated lymphoid tissue is a general term that includes BALT (bronchusassociated lymphoid tissue) and GALT (gastrointestinal lymphoid tissue). MALT lymphomas originate from the marginal zone B cells that surround the mantle zone and germinal center and are currently classified as a distinct subgroup of non-Hodgkin's lymphomas under the term extra-nodal marginal zone B-cell lymphoma of MALT-type (45). SS patients have a disproportionate tendency to develop lymphoproliferative disorders with lymphomas arising mainly in mucosal extranodal sites including the salivary and lacrimal glands, stomach and lung. Low-grade marginal zone B-cell lymphomas are the most common (46), but high-grade diffuse large B-cell lymphoma may also occur.

Primary pulmonary lymphomas are uncommon, representing less than $1 \%$ of lung cancers (47), and fewer than $1 \%$ of malignant lymphomas (46). Clinically, more than $80 \%$ of patients present at an asymptomatic stage and the lymphoma is usually diagnosed incidentally on imaging (48). Given the indolent clinical course and relatively benign histologic features, BALT lymphomas have frequently been described as "pseudolymphoma" (49-51). In a series of 13 patients with BALT lymphoma, 2 were found to have underlying SS (48). The radiographic presentation of BALT lymphomas in this series was variable, with either lung nodules (62\%) or airspace consolidation with or without air bronchograms (39\%) and with bilateral disease in more than half of the patients.

Lymphadenopathy is characteristically absent. MALT lymphomas have a good prognosis at the time of diagnosis, and the prognosis is similar regardless of the involved organs. A study of 22 patients reported greater than $80 \%$ survival at 5 years (52).

\section{Pulmonary amyloidosis}

Amyloid is an amorphous, eosinophilic material with a typical apple green birefringence under polarized light after Congo red staining. Amyloid is composed of insoluble, nonbranching linear fibrils of protein which deposit in tissues, often causing organ impairment (53). 
In the lungs, four general clinical syndromes of amyloidosis are recognized: systemic (generalized), localized, diffuse, and pleural (54). All forms of pulmonary amyloidosis are most commonly of the AL type, which is a protein of immunoglobulin origin $(55,56)$.

$\mathrm{AL}$ amyloidosis is a well-recognized complication of SS, most often associated with nodular pulmonary amyloidosis but also with systemic amyloidosis in rare cases.

Nodular pulmonary amyloidosis is almost always localized and is usually an incidental finding on chest radiography. Amyloid nodules are commonly peripheral and subpleural in location, usually affect the lower lobes, may be bilateral, and may reach a diameter of 15 $\mathrm{cm}$. The prognosis of nodular amyloidosis is usually excellent $(57,58)$.

Systemic AL amyloidosis has only rarely been described in association with SS and there are only two case reports described so far in the literature $(59,60)$.

\section{Pleural involvement}

Pleural effusion is a rare manifestation of SS. There have only been nine previous reports in the literature of pleural effusion occurring as a specific complication of primary SS (61-67) (68). Pleural fluid in these cases was characterized by lymphocytosis, elevated levels of SSA/SS-B antibodies, and low complement levels. Pleural effusions in SS are so rare that their occurrence should always bring up the possibility of a second underlying autoimmune disorder, such as systemic lupus erythematosus or rheumatoid arthritis.

Pleural thickening is another rare manifestation of SS. In a series of 37 SS patients who had normal chest radiographs, only one had pleural thickening on HRCT (6).

\section{Pulmonary hypertension}

The diagnosis of pulmonary arterial hypertension $(\mathrm{PAH})$ requires right-heart catheterization, demonstrating an elevated mean pulmonary artery pressure (mPAP) $>25 \mathrm{~mm} \mathrm{Hg}$ at rest or $>30 \mathrm{~mm} \mathrm{Hg}$ during exercise with a normal pulmonary capillary wedge pressure $(<15 \mathrm{~mm}$ $\mathrm{Hg}$ ) in order to exclude significant left heart disease (69). It is a rare complication of primary SS and less than 50 cases have been described in the literature. Dyspnea in SS patients is commonly attributed to underlying ILD and a diagnostic workup for pulmonary hypertension is usually delayed. In a series by Launay (70), half of the patients had right heart failure at the time of diagnosis, with more than $80 \%$ of patients presenting with NYHA functional class III or IV. The severity of PAH in this series was attributed to the late diagnosis. Standard PAH therapy with or without immunosuppression can improve SSassociated PAH, although the best treatment strategy is yet to be defined (70).

\section{Conclusions}

SS is associated with multiple pulmonary manifestations extending from the upper airway to the alveolar space. Pulmonary involvement results in both increased morbidity and mortality. Cough and dyspnea are common symptoms and may portend a number of pulmonary manifestations. While clinical pulmonary involvement is relatively rare, pathologic evidence of lung injury is common. Therefore, pulmonary complaints should 
trigger appropriate evaluation including clinical exam, radiographic imaging and pulmonary function testing. On some occasions, surgical lung biopsy may be necessary for definitive diagnosis. Early identification and treatment is associated with improved outcome.

\section{References}

1. Fox RI. Sjögren's syndrome. Lancet. Jul 23; 2005 366(9482):321-31. [PubMed: 16039337]

2. Helmick CG, Felson DT, Lawrence RC, Gabriel S, Hirsch R, Kwoh CK, et al. Estimates of the prevalence of arthritis and other rheumatic conditions in the United States. Part I. Arthritis Rheum. Jan; 2008 58(1):15-25. [PubMed: 18163481]

3. Palm O, Garen T, Berge Enger T, Jensen JL, Lund M-B, Aaløkken TM, et al. Clinical pulmonary involvement in primary Sjogren's syndrome: prevalence, quality of life and mortality--a retrospective study based on registry data. Rheumatol. Oxf. Engl. Jan; 2013 52(1):173-9.

4. Ramos-Casals M, Solans R, Rosas J, Camps MT, Gil A, Del Pino-Montes J, et al. Primary Sjögren syndrome in Spain: clinical and immunologic expression in 1010 patients. Medicine (Baltimore). Jul; 2008 87(4):210-9. [PubMed: 18626304]

5. Yazisiz V, Arslan G, Ozbudak IH, Turker S, Erbasan F, Avci AB, et al. Lung involvement in patients with primary Sjögren's syndrome: what are the predictors? Rheumatol. Int. Aug; 2010 30(10):1317-24. [PubMed: 19844720]

6. Uffmann M, Kiener HP, Bankier AA, Baldt MM, Zontsich T, Herold CJ. Lung manifestation in asymptomatic patients with primary Sjögren syndrome: assessment with high resolution CT and pulmonary function tests. J. Thorac. Imaging. Oct; 2001 16(4):282-9. [PubMed: 11685093]

7. Cain HC, Noble PW, Matthay RA. Pulmonary manifestations of Sjögren's syndrome. Clin. Chest Med. Dec; 1998 19(4):687-699. viii. [PubMed: 9917960]

8. Doig JA, Whaley K, Dick WC, Nuki G, Williamson J, Buchanan WW. Otolaryngological aspects of Sjögren's syndrome. Br. Med. J. Nov 20; 1971 4(5785):460-3. [PubMed: 5125281]

9. Murano E, Hosako-Naito Y, Tayama N, Oka T, Miyaji M, Kumada M, et al. Bamboo node: primary vocal fold lesion as evidence of autoimmune disease. J. Voice Off. J. Voice Found. Sep; 2001 15(3):441-50.

10. Prytz S. Vocal nodules in Sjögren's syndrome. J. Laryngol. Otol. Feb; 1980 94(2):197-203. [PubMed: 7373123]

11. Parke AL. Pulmonary Manifestations of Primary Sjögren's Syndrome. Rheum. Dis. Clin. North Am. Nov; 2008 34(4):907-20. [PubMed: 18984411]

12. Papiris SA, Maniati M, Constantopoulos SH, Roussos C, Moutsopoulos HM, Skopouli FN. Lung involvement in primary Sjögren's syndrome is mainly related to the small airway disease. Ann. Rheum. Dis. Jan; 1999 58(1):61-4. [PubMed: 10343542]

13. Mathieu A, Cauli A, Pala R, Satta L, Nurchis P, Loi GL, et al. Tracheo-bronchial mucociliary clearance in patients with primary and secondary Sjögren's syndrome. Scand. J. Rheumatol. 1995; 24(5):300-4. [PubMed: 8533045]

14. Butnor, KJ.; Khoor, A. Collagen Vascular Diseases and Disorders of Connective Tissue. In: Tomashefski, JF., Jr, editor. Dail Hammar's Pulm. Pathol. [Internet]. Springer; New York: 2008. p. 722-59.[cited 2013 Apr 4]Available from: http://link.springer.com/chapter/ 10.1007/978-0-387-68792-6_20

15. Andoh Y, Shimura S, Sawai T, Sasaki H, Takishima T, Shirato K. Morphometric analysis of airways in Sjögren's syndrome. Am. Rev. Respir. Dis. Nov; 1993 148(5):1358-62. [PubMed: 8239176]

16. Tian X, Yi ES, Ryu JH. Lymphocytic interstitial pneumonia and other benign lymphoid disorders. Semin. Respir. Crit. Care Med. Oct; 2012 33(5):450-61. [PubMed: 23001800]

17. Papiris SA, Saetta M, Turato G, La Corte R, Trevisani L, Mapp CE, et al. CD4-positive Tlymphocytes infiltrate the bronchial mucosa of patients with Sjögren's syndrome. Am. J. Respir. Crit. Care Med. Aug; 1997 156(2 Pt 1):637-41. [PubMed: 9279251] 
18. Teruuchi S, Bando M, Hironaka M, Ohno S, Sugiyama Y. [Sjögren's syndrome with multiple bullae and pulmonary nodular amyloidosis]. Nihon Kokyūki Gakkai Zasshi J. Jpn. Respir. Soc. Dec; 2000 38(12):918-22.

19. Jagirdar J, Chikkamuniyappa S, Sirohi D, McCarthy MJ, Peters JI. Cystic lung lesions in Sjogren syndrome: analysis of lymphocyte subsets in tissue with clinico-radiologic-pathologic correlation. Ann. Diagn. Pathol. Feb; 2013 17(1):113-6. [PubMed: 22658853]

20. McGrath-Morrow S, Laube B, Tzou S-C, Cho C, Cleary J, Kimura H, et al. IL-12 overexpression in mice as a model for Sjögren lung disease. Am. J. Physiol. - Lung Cell. Mol. Physiol. Oct 1; 2006 291(4):L837-L846. [PubMed: 16751222]

21. Mandl T, Diaz S, Ekberg O, Hesselstrand R, Piitulainen E, Wollmer P, et al. Frequent development of chronic obstructive pulmonary disease in primary SS-results of a longitudinal follow-up. Rheumatology. May 1; 2012 51(5):941-6. [PubMed: 22258389]

22. Linstow M, Kriegbaum NJ, Backer V, Ulrik C, Oxholm P. A follow-up study of pulmonary function in patients with primary Sjögren's syndrome. Rheumatol. Int. 1990; 10(2):47-9. [PubMed: 2349433]

23. Pertovaara M, Korpela M, Saarelainen S, Laitinen J, Järvenpää R, Laippala P, et al. Long-term follow-up study of pulmonary findings in patients with primary Sjögren's syndrome. Scand. J. Rheumatol. 2004; 33(5):343-8. [PubMed: 15513685]

24. Fox, RI. Extraglandular Manifestations of Sjögren's Syndrome (SS): Dermatologic, Arthritic, Endocrine, Pulmonary, Cardiovascular, Gastroenterology, Renal, Urology, and Gynecologic Manifestations. In: Fox, RI.; Fox, CM., editors. Sjögren's Syndr. [Internet]. Springer; New York: 2012. p. 285-316.Available from: http://link.springer.com/chapter/10.1007/978-1-60327-957-4_17 [cited 2013 Apr 4]

25. Parambil JG, Myers JL, Lindell RM, Matteson EL, Ryu JH. Interstitial lung disease in primary Sjögren syndrome. Chest. Nov; 2006 130(5):1489-95. [PubMed: 17099028]

26. Ito I, Nagai S, Kitaichi M, Nicholson AG, Johkoh T, Noma S, et al. Pulmonary manifestations of primary Sjogren's syndrome: a clinical, radiologic, and pathologic study. Am. J. Respir. Crit. Care Med. Mar 15; 2005 171(6):632-8. [PubMed: 15579729]

27. Boitiaux J-F, Debray M-P, Nicaise-Roland P, Adle-Biassette H, Danel C, Clérici C, et al. Idiopathic interstitial lung disease with anti-SSA antibody. Rheumatol. Oxf. Engl. Dec; 2011 50(12):2245-50.

28. Elicker B, Pereira CA, de C, Webb R, Leslie KO. High-resolution computed tomography patterns of diffuse interstitial lung disease with clinical and pathological correlation. J. Bras. Pneumol. Publica a o Of. Soc. Bras. Pneumol. E Tisilogia. Sep; 2008 34(9):715-44.

29. Katzenstein AL, Fiorelli RF. Nonspecific interstitial pneumonia/fibrosis. Histologic features and clinical significance. Am. J. Surg. Pathol. Feb; 1994 18(2):136-47. [PubMed: 8291652]

30. Liebow AA, Carrington CB. Lymphocytic interstitial pneumonia. Am. J. Pathol. 1966; 48(36a)

31. Morris JC, Rosen MJ, Marchevsky A, Teirstein AS. LYmphocytic interstitial pneumonia in patients at risk for the acquired immune deficiency syndrome. Chest J. Jan 1; 1987 91(1):63-7.

32. Strimlan CV, Rosenow EC 3rd, Weiland LH, Brown LR. Lymphocytic interstitial pneumonitis. Review of 13 cases. Ann. Intern. Med. May; 1978 88(5):616-21. [PubMed: 646244]

33. Swigris JJ, Berry GJ, Raffin TA, Kuschner WG. Lymphoid interstitial pneumonia: a narrative review. Chest. Dec; 2002 122(6):2150-64. [PubMed: 12475860]

34. Misumi S, Lynch DA. Idiopathic pulmonary fibrosis/usual interstitial pneumonia: imaging diagnosis, spectrum of abnormalities, and temporal progression. Proc. Am. Thorac. Soc. Jun; 2006 3(4):307-14. [PubMed: 16738194]

35. Lynch DA. Fibrotic idiopathic interstitial pneumonia: high-resolution computed tomography considerations. Semin. Respir. Crit. Care Med. Aug; 2003 24(4):365-76. [PubMed: 16088558]

36. Myers JL, Colby TV. Pathologic manifestations of bronchiolitis, constrictive bronchiolitis, cryptogenic organizing pneumonia, and diffuse panbronchiolitis. Clin. Chest Med. Dec; 1993 14(4):611-22. [PubMed: 8313666]

37. Alasaly K, Muller N, Ostrow DN, Champion P, FitzGerald JM. Cryptogenic organizing pneumonia. A report of 25 cases and a review of the literature. Medicine (Baltimore). Jul; 1995 74(4):201-11. [PubMed: 7623655] 
38. King TE Jr, Mortenson RL. Cryptogenic organizing pneumonitis. The North American experience. Chest. Jul; 1992 102(1 Suppl):8S-13S. [PubMed: 1623812]

39. Bradley B, Branley HM, Egan JJ, Greaves MS, Hansell DM, Harrison NK, et al. Interstitial lung disease guideline: the British Thoracic Society in collaboration with the Thoracic Society of Australia and New Zealand and the Irish Thoracic Society. Thorax. Sep; 2008 63(Suppl 5):v1-58. [PubMed: 18757459]

40. Kobayashi H, Matsuoka R, Kitamura S, Tsunoda N, Saito K. Sjögren's syndrome with multiple bullae and pulmonary nodular amyloidosis. Chest. Aug; 1988 94(2):438-40. [PubMed: 3396429]

41. Schlegel J, Kienast K, Störkel S, Ferlinz R. [Primary pulmonary nodular amyloidosis and multiple emphysematous bullae in Sjögren syndrome]. Pneumol. Stuttg. Ger. Dec; 1992 46(12):634-7.

42. Bonner H Jr, Ennis RS, Geelhoed GW, Tarpley TM Jr. Lymphoid infiltration and amyloidosis of lung in Sjögren's syndrome. Arch. Pathol. Jan; 1973 95(1):42-4. [PubMed: 4682027]

43. Hubscher O, Re R, Iotti R. Cystic lung disease in Sjögren's syndrome. J. Rheumatol. Oct; 2002 29(10):2235-6. [PubMed: 12375340]

44. Ramos-Casals M, Tzioufas AG, Font J. Primary Sjögren's syndrome: new clinical and therapeutic concepts. Ann. Rheum. Dis. Mar; 2005 64(3):347-54. [PubMed: 15498797]

45. Graham BB, Mathisen DJ, Mark EJ, Takvorian RW. Primary pulmonary lymphoma. Ann. Thorac. Surg. Oct; 2005 80(4):1248-53. [PubMed: 16181848]

46. Voulgarelis M, Dafni UG, Isenberg DA, Moutsopoulos HM. Malignant lymphoma in primary Sjögren's syndrome: a multicenter, retrospective, clinical study by the European Concerted Action on Sjögren's Syndrome. Arthritis Rheum. Aug; 1999 42(8):1765-72. [PubMed: 10446879]

47. Miller DL, Allen MS. Rare pulmonary neoplasms. Mayo Clin. Proc. Mayo Clin. May; 1993 68(5): 492-8.

48. Imai H, Sunaga N, Kaira K, Kawashima O, Yanagitani N, Sato K, et al. Clinicopathological features of patients with bronchial-associated lymphoid tissue lymphoma. Intern. Med. Tokyo Jpn. 2009; 48(5):301-6.

49. Kurtin PJ, Myers JL, Adlakha H, Strickler JG, Lohse C, Pankratz VS, et al. Pathologic and clinical features of primary pulmonary extranodal marginal zone B-cell lymphoma of MALT type. Am. J. Surg. Pathol. Aug; 2001 25(8):997-1008. [PubMed: 11474283]

50. Koss MN, Hochholzer L, Nichols PW, Wehunt WD, Lazarus AA. Primary non-Hodgkin's lymphoma and pseudolymphoma of lung: a study of 161 patients. Hum. Pathol. Dec; 1983 14(12): 1024-38. [PubMed: 6642492]

51. SALTZSTEIN SL. PULMONARY MALIGNANT LYMPHOMAS AND PSEUDOLYMPHOMAS: CLASSIFICATION, THERAPY, AND PROGNOSIS. Cancer. Jul. 1963 16:928-55. [PubMed: 14043765]

52. Thieblemont $\mathrm{C}$, de la Fouchardière A, Coiffier B. Nongastric mucosa-associated lymphoid tissue lymphomas. Clin. Lymphoma. Mar; 2003 3(4):212-24. [PubMed: 12672270]

53. Röcken C, Sletten K. Amyloid in surgical pathology. Virchows Arch. Int. J. Pathol. Jul; 2003 443(1):3-16.

54. Chen KT. Amyloidosis presenting in the respiratory tract. Pathol. Annu. 1989; 24(Pt 1):253-73. [PubMed: 2654840]

55. Cordier JF, Loire R, Brune J. Amyloidosis of the lower respiratory tract. Clinical and pathologic features in a series of 21 patients. Chest. Dec; 1986 90(6):827-31. [PubMed: 3780328]

56. Gertz MA, Greipp PR. Clinical aspects of pulmonary amyloidosis. Chest. Dec; 1986 90(6):790-1. [PubMed: 3780324]

57. Himmelfarb E, Wells S, Rabinowitz JG. The radiologic spectrum of cardiopulmonary amyloidosis. Chest. Sep; 1977 72(3):327-32. [PubMed: 891285]

58. Rubinow A, Celli BR, Cohen AS, Rigden BG, Brody JS. Localized amyloidosis of the lower respiratory tract. Am. Rev. Respir. Dis. Sep; 1978 118(3):603-11. [PubMed: 707881]

59. Perlat A, Decaux O, Gervais R, Rioux N, Grosbois B. Systemic light chain amyloidosis and Sjogren syndrome: an uncommon association. Amyloid Int. J. Exp. Clin. Investig. Off. J. Int. Soc. Amyloidosis. 2009; 16(3):181-2. 
60. Delèvaux I, André M, Amoura Z, Kémény JL, Piette JC, Aumaître O. Concomitant diagnosis of primary Sjögren's syndrome and systemic AL amyloidosis. Ann. Rheum. Dis. Jul; 2001 60(7): 694-5. [PubMed: 11406525]

61. Ogihara T, Nakatani A, Ito H, Irokawa M, Ban S, Takahashi A, et al. Sjögren's syndrome with pleural effusion. Intern. Med. Tokyo Jpn. Aug; 1995 34(8):811-4.

62. Alvarez-Sala R, Sánchez-Toril F, García-Martínez J, Zaera A, Masa JF. Primary Sjögren syndrome and pleural effusion. Chest. Dec; 1989 96(6):1440-1. [PubMed: 2582863]

63. Kashiwabara K, Kishi K, Narushima K, Nakamura H, Yagyu H, Kiguchi T, et al. [Primary Sjögren's syndrome accompanied by pleural effusion]. Nihon Kyōbu Shikkan Gakkai Zasshi. Nov; 1995 33(11):1325-9. [PubMed: 8583730]

64. Suzuki H, Hickling P, Lyons CB. A case of primary Sjögren's syndrome, complicated by cryoglobulinaemic glomerulonephritis, pericardial and pleural effusions. Br. J. Rheumatol. Jan; 1996 35(1):72-5. [PubMed: 8624627]

65. Kawamata K, Haraoka H, Hirohata S, Hashimoto T, Jenkins RN, Lipsky PE. Pleurisy in primary Sjögren's syndrome: T cell receptor beta-chain variable region gene bias and local autoantibody production in the pleural effusion. Clin. Exp. Rheumatol. Apr; 1997 15(2):193-6. [PubMed: 9196874]

66. Tanaka A, Tohda Y, Fukuoka M, Nakajima S. [A case of Sjögren's syndrome with pleural effusion]. Nihon Kokyūki Gakkai Zasshi J. Jpn. Respir. Soc. Aug; 2000 38(8):628-31.

67. Horita Y, Miyazaki M, Kadota J, Watanabe T, Yamashita M, Nishiura K, et al. Type II diabetes mellitus and primary Sjögren's syndrome complicated by pleural effusion. Intern. Med. Tokyo Jpn. Nov; 2000 39(11):979-84.

68. Teshigawara K, Kakizaki S, Horiya M, Kikuchi Y, Hashida T, Tomizawa Y, et al. Primary Sjogren's syndrome complicated by bilateral pleural effusion. Respirol. Carlton Vic. Jan; 2008 13(1):155-8.

69. Galiè N, Hoeper MM, Humbert M, Torbicki A, Vachiery J-L, Barbera JA, et al. Guidelines for the diagnosis and treatment of pulmonary hypertension. Eur. Respir. J. Off. J. Eur. Soc. Clin. Respir. Physiol. Dec; 2009 34(6):1219-63.

70. Launay D, Hachulla E, Hatron P-Y, Jais X, Simonneau G, Humbert M. Pulmonary arterial hypertension: a rare complication of primary Sjögren syndrome: report of 9 new cases and review of the literature. Medicine (Baltimore). Sep; 2007 86(5):299-315. [PubMed: 17873760] 


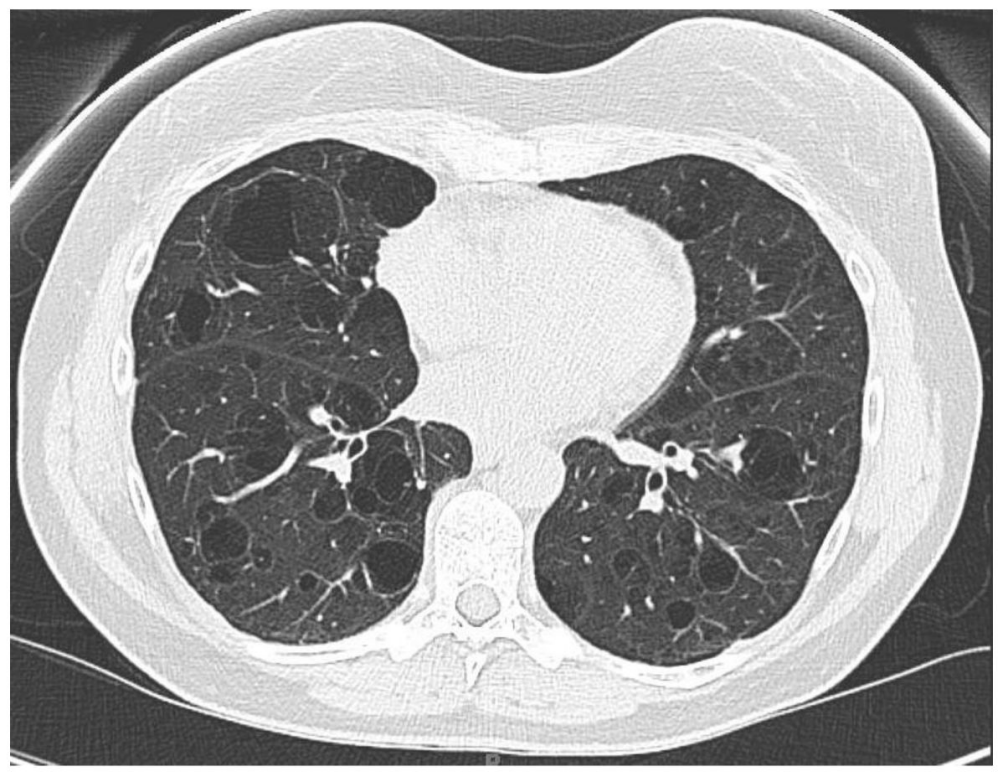

Figure 1.

Chest CT scan: Sjogren's syndrome associated cystic lung disease. A patient with longstanding primary SS underwent evaluation for new onset dyspnea on exertion. The patient was a lifelong non-smoker. Pulmonary function tests showed a mixed restrictive and obstructive pattern. The chest CT scan demonstrates extensive cystic changes. Subsequent surgical lung biopsy revealed follicular bronchiolitis as well as amorphous material that was consistent with lambda light chain deposition. 